\title{
INCONVENIENTES QUE SUSCITAN LAS CRISIS MATRIMONIALES CON ELEMENTOS INTERNACIONALES: COMENTARIO A LA SAP ZARAGOZA (SECCIÓN SEGUNDA) DE 16 DE NOVIEMBRE DE 2018
}

\author{
DIFFICULTIES ARISING FROM MARRIAGE CRISIS WITH \\ INTERNATIONAL ELEMENTS: COMMENTARY TO SAP \\ ZARAGOZA (SECOND SECTION) OF 16 NOVEMBER 2018
}

\author{
M Jesús SÁnChez CANo \\ Profesora Ayudante Doctora de Derecho Internacional Privado \\ Magistrado Suplente \\ Universidad San Jorge
}

Recibido: 17.06.2019 / Aceptado: 22.07.2019

DOI: https://doi.org/10.20318/cdt.2019.5021

\begin{abstract}
Resumen: La Sentencia de la Audiencia Provincial de Zaragoza conoce en sede de apelación de un divorcio que presenta elementos internacionales y que deja traslucir lo que se denomina conflicto de civilizaciones, en tanto que plantea los problemas que suscita el divorcio revocable islámico, institución ésta que no está contemplada en nuestro Derecho positivo y que incluso, puede resultar contraria al orden púbico internacional español. Junto a ello, la citada resolución resuelve otras cuestiones igualmente interesantes desde la perspectiva del Derecho Internacional privado, como son el importe fijado como pensión de alimentos a favor del hijo menor del matrimonio y la atribución del uso de la vivienda familiar al menor y a su madre.
\end{abstract}

Palabras clave: repudio, alimentos, uso de vivienda familiar.

Abstract: The Sentence of the Provincial Court of Zaragoza hears an appeal of a divorce that presents international elements and that allows the so called conflict of civilizations to shine through, while it raises the problems raised by the unilateral Islamic repudiation. This institution is not contemplated in our positive Law and may even be contrary to the Spanish international public policy. In addition, the resolution resolves other questions that are equally interesting from the perspective of Private International Law, such as the amount fixed as maintenance in favour of the minor child of the marriage and the attribution of the use of the family home to the minor and his mother.

Keywords: repudiation, alimony, use of family housing.

Sumario: I. Introducción. II. La SAP Zaragoza 16 Noviembre 2018: Breve descripción de los hechos. III. La SAP Zaragoza 16 Noviembre 2018: Análisis de los fundamentos de Derecho. A) Instituciones por las que se disuelve el matrimonio en Derecho islámico. B) Exequátur de la resolución marroquí por cual se acuerda el "divorcio revocable reservándose el esposo el derecho de reintegrarla al matrimonio." C) La solicitud de alimentos a favor del hijo menor de la pareja y la atribución del uso de la vivienda familiar al hijo menor y a su madre. Cuestiones de Derecho Internacional privado. IV. Conclusiones. 


\section{Introducción}

1. En los últimos tiempos, debido a las distintas concepciones de las relaciones familiares y junto con el notable incremento de las situaciones de crisis matrimoniales que presentan un elemento de extranjería, se han constatado una serie de inconvenientes, que se ven acrecentados por la divergencias existentes en los ordenamientos jurídicos de los Estados y que, en la mayor parte de las ocasiones, se deben a diferencias sociales, culturales y religiosas ${ }^{1}$.

2. En particular, las dificultades surgen cuando la institución procedente del Derecho extranjero resulta desconocida en nuestro país, o también, en aquellos casos en los cuales los efectos de aplicar dicho Derecho extranjero contravienen nuestro orden público internacional. Tal es el caso del repudio, institución procedente del Derecho islámico, cuya función consiste en la disolución del vínculo matrimonial y que puede resultar contrario a nuestros principios fundamentales, sobre todo, si se trata de un repudio unilateral. Los problemas que suscita el repudio pueden plantearse en los distintos sectores del Derecho Internacional privado, dado que ante los Tribunales españoles se presentan demandas tanto solicitando el repudio como su reconocimiento y efectos. En concreto, la Sentencia analizada valora el divorcio revocable de Derecho marroquí desde la perspectiva del sector de la validez extraterritorial de decisiones, para lo cual, entre otras premisas, tiene en cuenta el contenido y alcance de dicha institución.

3. Igualmente, al igual que sucede en las situaciones meramente internas, vinculadas a las crisis matrimoniales con elementos internacionales, aparecen otra serie de pretensiones para cuya solución también se precisa del Derecho Internacional privado, como son la guarda y custodia, régimen de visitas respecto de hijos menores, la pensión de alimentos, la disolución del régimen económico matrimonial o la atribución del uso de la vivienda familiar. Dichas cuestiones también son objeto de tratamiento por la Audiencia Provincial de Zaragoza en la resolución comentada.

4. Aquí, debe ponerse de relieve que, en muchas ocasiones, por parte del juez o tribunal, se comete el error de acudir directamente a la ley española, obviando que cuando se trata de resolver un litigio con elementos heterogéneos, para la determinación de la concreta ley aplicable que regulará la situación, debe acudir a la correspondiente norma de conflicto. Ello, habida cuenta la imperatividad de la norma de conflicto, de la cual se desprende que el juez o tribunal ha de aplicar de oficio las normas de conflicto españolas, independientemente de que las partes las aleguen o fundamenten en ellas sus pretensiones (art.12.6 Cc).

5. Todos estos temas se abordarán a través del comentario de la SAP Zaragoza (Sección Segunda) de 16 de Noviembre de 20182, en el cual se analizarán algunas de las cuestiones vinculadas a un divorcio internacional con elementos de extranjería y el tratamiento que han recibido por parte del Tribunal.

\section{La SAP Zaragoza 16 Noviembre 2018: Breve descripción de los hechos}

6. La resolución comentada resuelve un recurso de apelación formulado por la parte demandada en primera instancia frente a la Sentencia por la que se declara el divorcio de un matrimonio, respecto del cual se constata que presenta, al menos, un elemento de extranjería, cual es el lugar de celebración, dado que se afirma que el matrimonio se contrajo en Marruecos. La pareja, de la que no consta expre-

\footnotetext{
${ }^{1}$ Cabe traer aquí a colación lo que se ha denominado el conflicto de civilizaciones, que surge ante las distintas formas de regular las relaciones sociales, que, en ocasiones, resultan inconciliables. Vid. A.L. Calvo CaravaCa y J. CARrascosa GonzÁLEZ, Derecho Internacional Privado, Vol.II, Decimoctava Edidción, Granada, Comares, 2018, p.229.

${ }^{2}$ Sentencia de la Audiencia Provincial de Zaragoza (Sección 2a) Sentencia num. 511/2018 de 16 noviembre (ECLI: ECLI:ES:APZ:2018:2181.)
} 
samente su nacionalidad, reside en Zaragoza en el momento de interposición de la demanda, y tiene en común un hijo menor de edad.

7. Como motivo del recurso, cuya desestimación se insta por la parte apelada, se alega:

$\left.1^{\circ}\right)$ La nulidad de pleno derecho del procedimiento por carencia de objeto y cosa juzgada, en tanto que se interpuso en su día procedimiento de divorcio, en el que se dictó auto acordando no continuar el procedimiento por carencia de objeto, al haberse solicitado la disolución por divorcio de un matrimonio ya disuelto en Marruecos. En tal sentido, se aporta fotocopia de acta de divorcio en Marruecos, denominado "divorcio revocable reservándose el esposo el derecho de reintegrarla al matrimonio". El apelante aduce que no tuvo conocimiento de la resolución por la cual no se admitió a trámite, por inadecuación de procedimiento, la demanda de guarda, custodia y alimentos de hijo menor no matrimonial, que reside habitualmente en Zaragoza, pero, respecto del que no se dice en la sentencia cual es su nacionalidad. La causa de dicha inadmisión fue, justamente, el hecho de continuar casados en España por no haberse tramitado el exequátur para el reconocimiento de la sentencia de divorcio, necesario por no tratarse de un país de la Unión Europea.

$2^{\circ}$ ) Error en la apreciación de la prueba, sobre la base de que no es posible dictar resolución alguna frente al divorcio ni medidas relativas al mismo, dado que no cabe su tramitación y resolución, pues las partes ya se divorciaron en Marruecos, si bien el hijo común nació después del divorcio y cuando el apelante estaba casado con otras mujeres. Refiere asimismo que se encuentra en situación de incapacidad laborar sin derecho a prestación y que la esposa carece de derecho sobre un piso propiedad exclusiva del recurrente.

8. Por su parte, el Ministerio Fiscal impugna la sentencia con fundamento en el error de derecho y valoración de prueba en lo relativo a la atribución del uso de la vivienda, solicitando la extensión del mismo en favor del hijo menor y la madre.

\section{La SAP Zaragoza 16 Noviembre 2018: Análisis de los fundamentos de Derecho}

9. A la vista de los motivos del recurso de apelación y de la impugnación del Ministerio Fiscal, son tres las cuestiones controvertidas que se dilucidan en la Sentencia de la Audiencia Provincial y en las cuales se centrará el presente trabajo, dado que de todas ellas pudieran derivarse problemas que requieren tratamiento desde el punto de vista del Derecho Internacional privado:

$1^{\text {a) }}$ El valor que cabe dar al denominado "divorcio revocable reservándose el esposo el derecho de reintegrarla al matrimonio", así como, en su caso, el instrumento aplicable para otorgar el exequátur a la resolución por la que se decreta dicho divorcio, dictada por las autoridades marroquíes.

$2^{\text {a }) ~ L a ~ s o l i c i t u d ~ d e ~ a l i m e n t o s ~ a ~ f a v o r ~ d e l ~ h i j o ~ m e n o r ~ d e ~ l a ~ p a r e j a . ~}$

$3^{\mathrm{a}}$ ) La atribución del uso de la vivienda familiar al hijo menor y a su madre.

10. Para una mejor comprensión de esta controvertida cuestión, el presente epígrafe se estructurará en tres partes diferenciadas. Así, se comenzará introduciendo algunas notas explicativas acerca de las instituciones por las que se disuelve el matrimonio, propias de los ordenamientos jurídicos musulmanes. El estudio del tema requiere entender cuál es la posición jurídica en la que se encuentra la mujer musulmana respecto de este tipo de figuras, en ocasiones, desconocidas en el Derecho español. Seguidamente, se abordará el análisis del posible exequátur de la resolución marroquí por la cual se acuerda el denominado "divorcio revocable reservándose el esposo el derecho de reintegrarla al matrimonio." Por último, se considerarán las pretensiones relativas a la solicitud de alimentos y a la atribución del uso de la vivienda familiar. 


\section{A) Instituciones por las que se disuelve el matrimonio en Derecho islámico}

11. De manera general, las modalidades de disolución de un matrimonio islámico son las siguientes: nulidad absoluta y relativa del matrimonio, disolución por fallecimiento de alguno de los cónyuges, repudio unilateral y extrajudicial o talaq, repudio consensual mediante compensación o hul y la disolución judicial o trafriqat ${ }^{3}$. El presente análisis se centrará en el repudio o talaq, por su mayor similitud con la institución extranjera objeto de tratamiento en la sentencia estudiada.

12. En principio, el talaq comporta la facultad discrecional del esposo de dar por terminado el matrimonio, sin que se requiera motivo alguno, ni el consentimiento de la esposa. Tampoco es necesaria la intervención de una autoridad pública o judicial. Igualmente, el repudio o talaq puede configurarse con carácter revocable o irrevocable. Para entender cuando un repudio se considera revocable o irrevocable, hay que puntualizar que, tradicionalmente, se ha configurado como irrevocable el repudio que se ha pronunciado por tres veces, mientras que es revocable en el supuesto de que únicamente se haya formulado dos veces ${ }^{4}$. Ahora bien, en un momento posterior, se permitió el repudio irrevocable a través de una sola fórmula, con valor legal de tres. Es el marido, entonces, quien por su mera voluntad, elige si el repudio es irrevocable o tiene efectos suspensivos. La consecuencia del repudio irrevocable es la disolución automática del matrimonio 5 .

13. Dicho esto, en el caso estudiado, el divorcio en cuestión se ha decretado en Marruecos. A este respecto, hay que indicar que en dicho país la regulación de las distintas formas de disolución del matrimonio está recogida en el Código de Familia o Mudawana ${ }^{6}$, que aunque se inspira en la sharia, desde la última modificación, reforma el estatuto de las mujeres y en materia de matrimonio y divorcio, incorpora en mayor medida el principio de igualdad entre los cónyuges ${ }^{7}$. Más en concreto, la Mudawana regula el matrimonio nulo o viciado (arts.56-64), junto con su disolución, que podrá ser por fallecimiento, divorcio legalmente pronunciado, divorcio judicial -Tatliq-o divorcio consensual retribuido $-J o l^{\prime}-(\operatorname{art} .71)$. En todo caso, el divorcio requiere control judicial ${ }^{8}$ y su solicitud está permitida a ambos cónyuges, si bien, cada uno de ellos con sus condiciones (art.78)9.

14. Por lo demás, la Mudawana establece que el divorcio podrá ser revocable-Ray'i-o irrevocable-Báin-. En principio, todo divorcio decretado judicialmente será irrevocable, a excepción del di-

${ }^{3}$ Vid. Z. Combalía Solís, "Estatuto de la Mujer en el Derecho Matrimonial Islámico", Aequalitas: Revista jurídica de igualdad de oportunidades entre mujeres y hombres, $\mathrm{N}^{\circ}$ 6, 2001, p. 19.

${ }^{4}$ Así lo explica la Dra. Zoila Combalía, con fundamento en el pasaje coránico que se transcribe a continuación: “"El repudio se permite dos veces. Entonces, o se retiene a la mujer tratándola como se debe, o se la deja marchar de buena manera" (2, 229). Vid. Z. Combalía Solís, "Estatuto de la Mujer ...cit.", pp. 19 y 20.

${ }^{5}$ En lo referente al repudio con carácter revocable, conviene precisar que durante el periodo de continencia o espera legal (idda), el marido conserva el derecho a retractarse y a proseguir la vida conyugal. Vid. Z. Combalía Solís, "Estatuto de la Mujer ...cit.", p. 20.

${ }^{6}$ Dahir ${ }^{\circ}$ 1-04-22 du 12 hija 1424 (3 fevrier 2004) portant promulgation de la LOI No 70-03 portant Code de la Famille( Bulletin Officiel n ${ }^{\circ} 5358$ du 2 Ramadan 1426 ( 6 Octobre 2005 ), p. 667 ). El texto en árabe se publicó en Bulletin Officiel (édition générale) $\mathrm{n}^{\circ} 5184$ du 14 hija 1424 (5 février 2004) p. 418.

${ }^{7}$ A. Chaкkor, "La Mudawana. El Código de familia en Marruecos", http://intermigra.info/archivos/Mudawana.pdf.

${ }^{8}$ La intervención y el control judicial del divorcio constituye una garantía para los derechos de la esposa, como así lo entiende, M. D. Cervilla Garzón en "La aplicabilidad de las normas del Código de Familia marroquí (la Mudawana) que regulan el divorcio en España: el filtro constitucional”, Cuadernos de Derecho Transnacional, (Marzo 2018), Vol. 10, No 1, pp. 144-163.

${ }^{9}$ Concretamente, se contempla el divorcio judicial a petición de uno de los cónyuges por motivos de discordias o chiqaq (arts.94 y ss) y el divorcio judicial por otras causas, especificándose aquellas por las que la mujer puede solicitarlo en el art.98 de la Mudawana.

Por lo demás, se ha puesto de relieve que la regulación de las formas de disolución del matrimonio en la Mudawana incorpora el principio de igualdad de los cónyuges sólo en apariencia. Tómese como ejemplo el art.78, del cual parece desprenderse dicha igualdad, que queda desvirtuada más adelante, en el art.89, del cual se infiere que el esposo otorga a la esposa la facultad de disolución del matrimonio. Vid. M. D. Cervilla Garzón en "La aplicabilidad de las normas del Código de Familia marroquí (la Mudawana)...cit", p.147. 
vorcio judicial por juramento de continencia y el divorcio por falta de manutención económica (art.122). Ahora bien, el divorcio a iniciativa del marido será revocable, con la salvedad del que "tiene lugar después de dos divorcios anteriores consecutivos, el divorcio anterior a la consumación del matrimonio, el divorcio de mutuo acuerdo, el divorcio consensual retribuido ( $\mathrm{Jol}$ ') y el divorcio que resulte de un derecho de opción consentido por el marido a su mujer (art.123). Además, el esposo podrá reanudar la convivencia con su mujer durante el período de espera legal (Idda), pero, transcurrido este periodo, la mujer quedará definitivamente separada de su marido (arts.124 y 125).

15. Consta en el procedimiento analizado acta de divorcio revocable, que, con arreglo al art.138 de la Mudawana, "debe ser levantada por dos adul, legalmente habilitados a tal efecto, después de autorizarlo el tribunal, y previa presentación de un documento que certifique el matrimonio." De la misma manera, la Sentencia estudiada aprecia que de lo actuado se desprende que el esposo reintegró a la esposa al matrimonio, habiendo convivido con posterioridad, dado que de dicha convivencia nació un hijo que figura inscrito como matrimonial.

\section{B) Exequátur de la resolución marroquí por cual se acuerda el "divorcio revocable reservándose el esposo el derecho de reintegrarla al matrimonio"}

16. Sobre esta cuestión y dado que el apelante alega la existencia de cosa juzgada, primeramente, hay que dejar sentado que para que la sentencia marroquí surta efectos en nuestro país es necesario el reconocimiento y exequátur. Ello incluye el pretendido efecto de cosa juzgada, que no podrá tener nunca lugar sin que se otorgue el reconocimiento de la sentencia extranjera por los tribunales españoles ${ }^{10}$. En este punto, cabe distinguir entre el efecto de cosa juzgada material en sentido positivo y el efecto de cosa juzgada material en sentido negativo. De este modo, el efecto de cosa juzgada material en sentido positivo comporta que las autoridades españolas quedan vinculadas por la sentencia extranjera como si hubiese sido dictada por los tribunales españoles. Mientras, el efecto de cosa juzgada material en sentido negativo supone que no es posible reproducir ante los tribunales españoles un litigio ya resuelto por las autoridades extranjeras ${ }^{11}$.

17. Respecto al reconocimiento y ejecución de resoluciones extranjeras en materia de crisis matrimoniales, primeramente, hay que indicar que en nuestro país existen distintos instrumentos legales que reglamentan la cuestión. Así, el Reglamento Bruselas II-bis de 27 de noviembre de 2003, procedente del legislador de la Unión Europea y que opera respecto de resoluciones de nulidad, separación judicial y divorcio dictadas por las autoridades públicas de los Estados miembros, a excepción de Dinamarca. El

${ }^{10}$ Vid. SAP Lugo 23 septiembre 2004 (CENDOJ 27028370012004100458) y SAP Asturias 29 septiembre 2006 (CENDOJ 33304470042006100344), SAP Barcelona 20 octubre 2015 JUR 2015\281610), SAP Barcelona 17 mayo 2016 (JUR 2016\181620) y SAP La Rioja 4 mayo 2017 (JUR 2017\161027), SAP Barcelona 1317/2019 (ECLI:ES:APB:2019:1317), entre otras muchas. Consúltese también, Aurelio Lopez-Tarruella Martinez, "El reconocimiento de decisiones extranjeras de divorcio, separación judicial y nulidad matrimonial en España", Revista de la Facultad de Ciencias Sociales y Jurídicas, Núm. 1-2006, Julio 2006. Recuperado en https://2019-vlex-com.ezproxy.uned.es/\#search/jurisdiction:ES+content_type:4/exequátur + sentencias+divorcio+marroqu $\%$ C3\%ADes/WW/vid/217310749.

En este punto, hay que advertir que no es pacífica la doctrina jurisprudencial seguida en esta resolución, dado que otros tribunales han sostenido que, a pesar de no concurrir el efecto de cosa juzgada, debido a la falta de exequátur, no cabe reproducir la cuestión en otro procedimiento por las mismas partes y la misma causa. Vid, en este sentido, SAP Barcelona 10 septiembre 2010 (JUR 2010\375792) y AAP Cádiz 26 septiembre 2017 (JUR 2017\302496).

${ }^{11}$ El reconocimiento procesal supone que las resoluciones extranjeras desplegarán efectos en nuestro país si cumplen con los requisitos previstos a tal efecto en reglas de Derecho procesal civil internacional. Esta solución se circunscribe a los efectos de naturaleza procesal (efecto de cosa juzgada material, efecto constitutivo y efecto de tipicidad) de las decisiones dictadas por la autoridad extranjera. De otro lado, los efectos ejecutivos derivan del procedimiento de exequátur o declaración de ejecutividad, por el cual una resolución extranjera se transforma en un título ejecutivo y podrá ser ejecutada como si se tratase de un título nacional. Vid. A.L. Calvo Caravaca y J. Carrascosa González, Derecho Internacional Privado, Vol.I, pp.383 y ss. y.I Vol.II, Decimoctava Edición, Granada, Comares, 2018, p. 296, así como Calvo Caravaca, J. Carrascosa GonzÁlez, M.A. Cebrián Salvat, "Tema IV: Eficacia extraterritorial de decisiones”, en A.L. Calvo Caravaca y J. Carrascosa GonzÁlez (Directores), Compendio de Derecho Internacional Privado, Murcia, 2019, pp.162-165. 
citado Reglamento prevalece en todo lo cubierto por él sobre determinados Convenios ${ }^{12}$, así como sobre las normas de producción interna españolas, que en el sector de la validez extraterritorial de decisiones se recogen en los arts.41-61 de la Ley de Cooperación Jurídica Internacional en Materia Civil de 2015 (LCJIMC 2015).

18. No obstante, en el caso objeto de litigio, en consonancia con lo dispuesto por la Audiencia Provincial, tratándose de una decisión procedente de una autoridad marroquí, no debe perderse de vista que España y Marruecos suscribieron el Convenio de Cooperación Judicial en Materia Civil, Mercantil y Administrativa entre el Reino de España y el Reino de Marruecos, firmado en Madrid el 30 de mayo de 1997 (BOE núm. 151, de 25 de junio de 1997). El citado Convenio resulta aplicable al presente caso, habida cuenta la prevalencia de los Tratados internacionales sobre la LCJIM 2015, teniendo en cuenta el carácter subsidiario de la misma (art.2 LCJIMC 2015) ${ }^{13}$.

19. En virtud del art.22 del citado Convenio, las resoluciones en materia de crisis matrimoniales dictadas por alguno de los dos Estados Contratantes tendrán autoridad de cosa juzgada y fuerza ejecutiva en el otro Estado si se cumplen las condiciones del art. $23^{14}$. En cuanto a la ejecución, conforme al art.26 el tribunal competente únicamente verificará si la resolución reúne los requisitos del art. 23 para desplegar el efecto de cosa juzgada. No obstante, deberá atenderse aquí a lo dispuesto art. 25, con arreglo al cual, la concesión del derecho a la ejecución de la resolución y el procedimiento de ejecución se gobernarán por la Ley del Estado en que se solicite la ejecución de la resolución.

20. Respecto a los motivos del art. 23 del Convenio hispano-marroquí, parece oportuno detenerse brevemente en lo referente al orden público internacional, estipulado en el apartado 4. En este sentido, siendo el divorcio marroquí al que alude la sentencia un divorcio revocable es posible plantearse si la misma pudiera ser contraria a nuestro orden público internacional. A este respecto, deben formularse una serie de consideraciones ${ }^{15}$ :

${ }^{12}$ El Reglamento prevalece sobre los Convenios bilaterales firmados por España con otros Estados: Convenio hispano-alemán 1983, Convenio hispano-austriaco 1984, Convenio hispano-italiano 1973, Convenio hispano-francés 1969. Así lo indican Calvo Caravaca, J. Carrascosa González, M.A. Cebrián Salvat, “Tema IV: Eficacia extraterritorial de ...cit”, en A.L. Calvo Caravaca y J. Carrascosa González (Directores), Compendio de Derecho Internacional Privado, Murcia, 2019, p.332.

${ }^{13}$ La aplicación de dicho Convenio ha sido admitida por la jurisprudencia menor, sirvan así de ejemplos, por citar algunas resoluciones recientes, la SAP Murcia 00007/2018 ( ECLI:ES:APMU:2018:1104), de 11 de enero de 2018 el AAP Sevilla 905/2018, de 23 de marzo de 2018 (ECLI: ES:APSE:2018:905A), SAP Barcelona 1317/2019 (ECLI:ES:APB:2019:1317), entre otras. A favor de la aplicación del Convenio hispano-marroquí se muestran igualmente A. LoPEZ-TARRUELLA MARTINEZ, "El reconocimiento de decisiones extranjeras de divorcio, separación judicial y nulidad matrimonial en España", Revista de la Facultad de Ciencias Sociales y Jurídicas, Núm. 1-2006, Julio 2006. Recuperado en https://2019-vlex-com.ezproxy.uned. es/\#search/jurisdiction:ES+content_type:4/exequátur+sentencias+divorcio+marroqu\%C3\%ADes/WW/vid/217310749; $\quad$ C. CARrillo Lerma, en "Divorcio en España entre cónyuges marroquíes: la Sentencia de la Audiencia Provincial de Barcelona de 30 diciembre 2014”, Cuadernos de Derecho Transnacional, (Octubre 2015), Vol. 7, No 2, pp. 416-417; así como, Á. M. Ballesteros Barros, "Res iudicata y divorcio internacional: nota al Auto de la Audiencia Provincial de Toledo de 7 de marzo de 2018”, Cuadernos de Derecho Transnacional (Marzo 2019), Vol. 11, No 1, pp. 678-684.

${ }^{14}$ Artículo 23.

Las resoluciones judiciales en materia civil, mercantil y administrativa, dictadas por los órganos jurisdiccionales competentes de España y Marruecos, respectivamente, tendrán autoridad de cosa juzgada en el territorio del otro Estado, si reúnen las condiciones siguientes:

1.La resolución emana de un órgano jurisdiccional competente según las normas aplicables en el país en que hubiera sido dictada;

2. Las partes han sido legalmente citadas, representadas o declaradas rebeldes;

3. La resolución ha adquirido autoridad de cosa juzgada y ha llegado a ser ejecutiva conforme a las leyes del Estado en que haya sido dictada;

4. La resolución no contiene disposiciones contrarias al orden público del Estado en que se solicite la ejecución, ni a los principios del derecho internacional que sean aplicables en el mismo. Tampoco deberá ser contraria a una resolución judicial dictada en ese mismo Estado y que haya adquirido autoridad de cosa juzgada;

5. Que no se encontrase pendiente ningún proceso entre las mismas partes y por el mismo objeto ante algún órgano jurisdiccional del Estado requerido antes de iniciarse la acción ante el tribunal que haya dictado la resolución que deba ejecutarse.

${ }^{15}$ Sobre este particular, Vid. A.L. Calvo Caravaca y J. Carrascosa González, Derecho Internacional Privado, Vol.II, Decimoctava Edición, Granada, Comares, 2018, pp.303 y 304. 
$\left.1^{a}\right)$ En el momento de solicitar el reconocimiento de la resolución extranjera el repudio o divorcio debe continuar siendo revocable, habida cuenta que, si ha transcurrido el plazo de continencia o espera legal sin que el esposo lo haya revocado, el repudio ya ha devenido irrevocable ${ }^{16}$.

$2^{\mathrm{a}}$ ) Entre los principios de orden público internacional español que vulnera un divorcio o repudio revocable, cabe mencionar: la estabilidad del estado civil ${ }^{17}$ y el principio de igualdad y no discriminación ${ }^{18}$, dado su carácter unilateral a favor del esposo, que es quien únicamente tiene la facultad para instarlo, sin que la esposa pueda intervenir en el procedimiento ${ }^{19}$.

$3^{\mathrm{a}}$ ) Si el divorcio o repudio vulnera nuestros principios de orden público internacional resulta obvio que la decisión extranjera que lo acuerda no podrá ser reconocida en España (art.46.1 LCJIMC 2015 y art.23.4 Convenio hispano-marroquí).

$4^{\mathrm{a}}$ ) No obstante lo dicho, existen determinados supuestos en los que cabe dar efectos jurídicos en España a una decisión extranjera de repudio, como por ejemplo, cuando es la propia esposa la que insta su eficacia, o si se trata de un divorcio consensual retribuido. Así lo ha entendido nuestro Tribunal Supremo ${ }^{20}$.

\section{C) La solicitud de alimentos a favor del hijo menor de la pareja y la atribución del uso de la vivien- da familiar al hijo menor y a su madre. Cuestiones de Derecho Internacional privado}

21. La Sentencia examinada contiene también otros dos pronunciamientos que pueden resultar de interés desde una perspectiva internacionalprivatista, dado que del supuesto en cuestión podría deducirse la presencia de elementos de extranjería. En este punto, debe hacerse notar que de los antecedentes de hecho de la resolución parece inferirse que los esposos en el momento de contraer matrimonio en Marruecos tenían la nacionalidad marroquí, si bien se desconoce si con posterioridad han adquirido la nacionalidad española por residencia. Tampoco consta la nacionalidad del hijo menor. El único dato que se conoce con certeza es que los esposos contrajeron matrimonio en Marruecos y que en el momento de interponer la demanda tanto los cónyuges como el hijo común menor de edad, residían en España.

22. Por otro lado, el Tribunal resuelve ambas pretensiones, la de alimentos a favor del menor y la atribución del uso de la vivienda familiar, como si se tratase de una situación interna, aplicando directamente el Derecho sustantivo español, sin el previo recurso a las normas de Derecho Internacional privado y particularmente, a las correspondientes normas de conflicto que designan la ley aplicable a cada pretensión.

23. En ambos casos, de detectarse la presencia de al menos un elemento extranjero que vincule la situación con diferentes sistemas jurídicos, hay que tener muy presente que la relación debe ser regulada por el Derecho Internacional Privado español, Por este motivo, dado su carácter imperativo, el tribunal debería haber aplicado de oficio las normas de conflicto correspondientes a cada pretensión (art.12.6 Cc), independientemente de que las partes las hubieran invocado o no y quedando descartada la aplicación del Derecho privado interno. Ello, por cuanto será la norma de conflicto la que lleve a cabo la localización de la pretensión en un Estado determinado, cuyo Derecho resolverá la controversia planteada. Facilitando la concreta solución sustantiva al supuesto litigioso ${ }^{21}$. Aquí, hay que matizar que la

16 Vid. ATS 18 mayo 2004 (CENDOJ 287091100120042001621).

${ }^{17}$ Vid., entre otras, RDGR 23 septiembre 2000 (RJ 2000/9349)

${ }^{18}$ Ténganse en cuenta aquí que el art. 5 del Protocolo $\mathrm{n}^{\circ} 7 \mathrm{del}$ CEDH establece la igualdad de los cónyuges en la disolución del matrimonio.

${ }^{19}$ Vid, por ejemplo, AAP Castellón 13 septiembre 2005 (CENDOJ 12040370022005100078).

${ }^{20}$ Vid. AATS 21 abril 1998 (ECLI:ES:TS1998:477ª y 27 enero 1998(CENDOJ 28079110011998200134), para cada uno de los casos enunciados.

${ }^{21}$ Así lo resolvió la SAP Zaragoza (Secc. 2a) 20 abril 2012 (CENDOJ: 50297370022012100172). Consúltese asimismo, SSTS 1 ABRIL 2011 (ECLI:ES:TS:2011:1805) y 17 abril 2015 (CENDOJ: 28079110012015100235), además de otras muchas procedentes de las distintas Audiencias Provinciales. 
imperatividad de las normas del Derecho de la Unión Europea no deriva del art.12.6 Cc, sino del art.288. II TFUE, para el caso de los Reglamentos, y del art.288.III, en el supuesto de las Directivas ${ }^{22}$.

24. Dicho esto, para determinar la ley aplicable a la solicitud de alimentos a favor del hijo menor habrá que acudir a las normas de conflicto del Protocolo de La Haya de 2007 sobre la Ley Aplicable a las Obligaciones Alimenticias, que tienen carácter universal y eficacia erga omnes (art.2) y cuyo art.3 establece que, como regla general, resultará de aplicación la ley del Estado de la residencia habitual del acreedor de alimentos. El citado Protocolo solventa el problema de la remisión a un sistema plurilegislativo, como es el español, con las reglas recogidas en los arts.16 y ss.

25. Por lo que respecta a la atribución del uso de la vivienda familiar, se ha venido entendiendo que se trata de un efecto que se desprende de la decisión judicial por la que se acuerda el divorcio y se sujeta a la concreta ley estatal que regula dicho efecto ${ }^{23}$. En este punto, se han concretado varias hipótesis, si bien, para aquellos supuestos en que, como en la sentencia estudiada, los cónyuges tienen hijos menores de edad, se considera que la atribución del uso y disfrute de la vivienda familiar constituye una medida de protección de menores. En consecuencia, si el hijo es menor de 18 años, para designar la ley aplicable operará el Convenio de La Haya de 1996 en materia de protección de menores, en cuyo caso, el tribunal aplicará su propia ley (art.15). El Convenio también dispone de normas para la solución del problema de la remisión a un sistema plurilegislativo, como el nuestro, en el art.48. Si se trata de un menor de edad conforme a su ley personal, pero, mayor de 18 años, la ley aplicable a la situación será la determinada por el art.9.6 Cc. ${ }^{24}$.

\section{Conclusiones}

26. En el presente trabajo se han examinado las tres pretensiones objeto del recurso de apelación que se resuelven por la SAP Zaragoza (Sección Segunda) de 16 de noviembre de 2017, toda vez que las mismas suscitan cuestiones de interés para el Derecho Internacional privado. Así, en relación con el posible efecto de cosa juzgada, en virtud de la sentencia marroquí por la que se declara el "divorcio revocable reservándose el esposo el derecho de reintegrarla al matrimonio", el sector involucrado es el de la validez extraterritorial de decisiones. Mientras que la solicitud de alimentos y la atribución del uso de la vivienda se encuadrarían dentro del sector de la ley aplicable, dejando al margen la competencia judicial internacional, que no ha sido objeto de estudio en este comentario. De este análisis han podido extraerse las siguientes conclusiones:

27. Primera: En cuanto a la primera de las pretensiones, cabe concluir que los argumentos de la Audiencia Provincial resultan acertados, habida cuenta que, en primer lugar, declara aplicable para otorgar, en su caso, el exequátur de la sentencia marroquí el Convenio de Cooperación Judicial en Materia Civil, Mercantil y Administrativa entre el Reino de España y el Reino de Marruecos, firmado en Madrid el 30 de mayo de 1997. Ello, por cuanto, tratándose de una resolución de un tercer Estado, que no forma parte de la Unión Europea, no resulta aplicable el sistema de reconocimiento del RBII Ibis y además, el Convenio prevalece, en todo lo regulado por él, sobre nuestra norma de producción interna, la LCJIMC 2015.

28. Segunda: En segundo término, igualmente correcto es el razonamiento del Tribunal en relación a la no existencia de cosa juzgada, pues resulta claro que dicho efecto sólo puede generarse mediante el reconocimiento por las autoridades españolas de la resolución marroquí de divorcio revocable.

\footnotetext{
${ }^{22}$ Así lo explican A.L. Calvo Caravaca y J. Carrascosa González, Derecho Internacional Privado, Vol.I, Decimoctava Edición, Granada, Comares, 2018, pp.207 y 208.

${ }^{23}$ Vid. SAP SC Tenerife 24 marzo 2006 (CENDOJ 38038370032006100135$)$.

${ }^{24}$ Vid. A.L. Calvo Caravaca y J. Carrascosa González, Derecho Internacional Privado, Vol.II, Decimoctava Edición, Granada, Comares, 2018, p.289.
} 
Dicho extremo no ha quedado acreditado en el presente caso, habida cuenta que no se ha podido constatar que ninguno de los esposos hubiera solicitado el exequátur de la sentencia por el procedimiento pertinente, que, como ya se ha visto, será el establecido en los arts.22 y ss. del Convenio hispano-marroquí antes citado. Más aún, cuando existen pruebas de que los esposos recuperaron la convivencia.

29. Tercera: Atendiendo a los razonamientos de la conclusión anterior y no apreciando el tribunal el efecto de cosa juzgada, es evidente que el Juez "a quo" y la propia Audiencia Provincial, pueden entrar a conocer de la demanda de divorcio, sin que, de ningún modo, se encuentren vinculados por el resultado de la sentencia marroquí, toda vez que no ha sido reconocida y no se ha producido el efecto de cosa juzgada en España.

30. Cuarta: De haberse solicitado el exequátur de la decisión marroquí, teniendo por objeto un divorcio revocable, podría haberse activado la excepción de orden público internacional, que operaría como causa de denegación del reconocimiento, con arreglo al art.23.4 del Convenio hispano-marrquí de 1997. Ello por los motivos explicados en los apartados anteriores: alteración del estado civil y vulneración del principio de igualdad y no discriminación. Aquí hay que tener en cuenta que no operaría la cláusula del orden público internacional si hubiera sido la esposa la que instara el reconocimiento de la resolución de divorcio revocable, toda vez que lo contrario podría ocasionarle graves perjuicios, al seguir constando como casada.

31. Quinta: En la resolución estudiada figuran ciertos datos de los que pudiera desprenderse que el objeto del litigio pudiera ser una situación privada internacional. En este sentido, consta en el procedimiento que los esposos contrajeron en Marruecos, de donde parece inferirse la presencia de otros elementos heterogéneos en esta relación. Sin embargo, ni las partes, ni el Juez "a quo", ni tampoco la Audiencia Provincial, en ningún momento hicieron referencia alguna a tales extremos, llegando al punto de resolver las cuestiones controvertidas aplicando directamente el Derecho sustantivo español. No obstante, de presentar estas situaciones al menos un elemento extranjero, la Audiencia Provincial debería haber constatado de oficio si se encontraba ante una situación privada internacional, independientemente de que las partes lo hubieran alegado o no. Ello, por cuanto el elemento extranjero no es un simple dato de hecho, sino un presupuesto jurídico de aplicación de las normas de conflicto. De concluir que el supuesto sí que presentaba conexión con más de un ordenamiento jurídico extranjero, la situación sería susceptible de generar un conflicto de leyes y en consecuencia, quedaría sujeta a las reglas del Derecho Internacional privado español.

32. Sexta: Ante una situación privada internacional, los tribunales españoles no pueden desconocer que la aplicación de las normas de conflicto es imperativa (art.12.6 Cc) y que en consecuencia, las han de aplicar de oficio. En el caso de la sentencia analizada, las normas de conflicto que designarían la ley aplicable a los alimentos serían las previstas en el Protocolo de La Haya de 2007, mientras que la atribución del uso de la vivienda familiar se regiría por lo dispuesto en el Convenio de La Haya de 1996, puesto que los cónyuges tienen un hijo menor de dieciocho años. 